\title{
Interstitial Fluid Colloid Osmotic Pressure in Healthy Children
}

\author{
Hans Jørgen Timm Guthe $e^{1,2 *}$, Marianne Indreb $\varnothing^{3}$, Torbjørn Nedreb $\varnothing^{4,5}$, Gunnar Norgård ${ }^{6}$, \\ Helge Wiig ${ }^{4}$, Ansgar Berg ${ }^{1,7}$ \\ 1 Department of Pediatrics, Haukeland University Hospital, Bergen, Norway, 2 Department of Clinical \\ Medicine, University of Bergen, Bergen, Norway, 3 Department of Clinical Medicine, Faculty of Medicine, \\ University of Oslo, Oslo, Norway, 4 Department of Biomedicine, University of Bergen, Bergen, Norway, \\ 5 Department of Occupational Medicine, Hyperbaric Medical Unit, Haukeland University Hospital, Bergen, \\ Norway, 6 Department of Clinical Medicine, Faculty of Medicine, Section for Pediatric heart-, lung- and \\ allergic diseases, University of Oslo, Oslo, Norway, 7 Department of Clinical Science, University of Bergen, \\ Bergen, Norway \\ * hjgu@ helse-bergen.no
}

\section{Abstract}

\section{G openaccess}

Citation: Guthe HJT, Indrebø M, Nedrebø T, Norgård G, Wiig H, Berg A (2015) Interstitial Fluid Colloid Osmotic Pressure in Healthy Children. PLoS ONE 10(4): e0122779. doi:10.1371/journal.pone.0122779

Academic Editor: Yoshihiro Fukumoto, Kurume University School of Medicine, JAPAN

Received: September 28, 2014

Accepted: February 7, 2015

Published: April 8, 2015

Copyright: @ 2015 Guthe et al. This is an open access article distributed under the terms of the Creative Commons Attribution License, which permits unrestricted use, distribution, and reproduction in any medium, provided the original author and source are credited.

Data Availability Statement: All relevant data are within the paper and its Supporting Information files.

Funding: This work was supported by research grants (HJTG received funding) from West Norway Regional Health Authority, grant number 911441 (http://www.helse-vest.no/no/FagOgSamarbeid/ forsking/Sider/default.aspx). The funder had no role in study design, data collection and analysis, decision to publish, or preparation of the manuscript.

Competing Interests: The authors have declared that no competing interests exist.

\section{Objective}

The colloid osmotic pressure (COP) of plasma and interstitial fluid play important roles in transvascular fluid exchange. COP values for monitoring fluid balance in healthy and sick children have not been established. This study set out to determine reference values of COP in healthy children.

\section{Materials and Methods}

COP in plasma and interstitial fluid harvested from nylon wicks was measured in 99 healthy children from 2 to 10 years of age. Nylon wicks were implanted subcutaneously in arm and leg while patients were sedated and intubated during a minor surgical procedure. COP was analyzed in a colloid osmometer designed for small fluid samples.

\section{Results}

The mean plasma COP in all children was $25.6 \pm 3.3 \mathrm{mmHg}$. Arbitrary division of children in four different age groups, showed no significant difference in plasma or interstitial fluid COP values for patients less than 8 years, whereas patients of 8-10 years had significant higher COP both in plasma and interstitial fluid. There were no gender difference or correlation between COP in interstitial fluid sampled from arm and leg and no significant effect on interstitial COP of gravity. Prolonged implantation time did not affect interstitial COP.

\section{Conclusion}

Plasma and interstitial COP in healthy children are comparable to adults and COP seems to increase with age in children. Knowledge of the interaction between colloid osmotic forces can be helpful in diseases associated with fluid imbalance and may be crucial in deciding different fluid treatment options. 


\title{
Trial Registration
}

\author{
ClinicalTrials.gov NCT01044641
}

\section{Introduction}

Maintenance of body fluid homeostasis requires a delicate balance between the hydrostatic and colloid osmotic pressure (COP) acting across the intravascular and interstitial compartments. According to the classical Starling hypothesis, the net fluid shift across the capillary membrane is based on the interaction between two opposing forces: the difference in hydrostatic pressures and COP on either side of the membrane separating the capillary and the interstitial fluid (IF) spaces [1]. Studies of these parameters under various conditions with fluid retention (e.g. nephrotic syndrome [2], premenstrual syndrome [3], normal pregnancy [4] and cardiopulmonary disease [5] ) in humans have had great significance for understanding the pathophysiology of these disorders, and have in some cases been important in the choice of fluid treatment [5]. The normal values for colloid osmotic and hydrostatic pressures in the resting state of healthy children have not been established, largely because of methodological difficulties in measurements of each of the parameters. In the case of interstitial colloid osmotic pressure $\left(\mathrm{COP}_{\mathrm{i}}\right)$, this is likely due to lack of generally accepted methods for isolating IF. What is clear, however, is that plasma colloid osmotic pressure $\left(\mathrm{COP}_{\mathrm{p}}\right)$ increases during the first months after birth, reaching at one year of age, values comparable to those reported in adult subjects [6]. Furthermore, decreased COP $\mathrm{p}_{\mathrm{p}}$ in disease states, like congenital analbuminemia and during surgery for congenital cardiac malformations, is associated with compromised pulmonary function and tissue edema $[7,8]$. A commonly accepted method for IF sampling and thus $\mathrm{COP}_{\mathrm{i}}$ determination is implantation of wicks $[9,10]$ within the proximity of the heart assuming that this position represents the average capillary pressure [11]. Gravity is thought to influence the transcapillary pressures measured below the heart level with decreased interstitial COP from an increased hydrostatic pressure gradient [11]. Harvesting IF has traditionally been managed by extraction of fluid from subcutaneously implanted nylon wicks [9]. Although evaluation studies have shown that an implantation time of 60 minutes is appropriate in adults, this supposition is not necessarily true for the pediatric population. Establishing normal values of $\mathrm{COP}_{\mathrm{i}}$ in healthy children can be vital for proper fluid therapy in critically ill children. The aim of this study was primarily to evaluate the relationship between $\mathrm{COP}_{\mathrm{p}}$ and $\mathrm{COP}_{\mathrm{i}}$ in healthy children of different age. Secondly, we wanted to test if gravity would induce a difference in $\mathrm{COP}_{\mathrm{i}}$ obtained from arm and leg and thirdly to evaluate implantation times of wicks of 60 and 90 minutes.

\section{Materials and Methods}

The study was designed as a non-blinded, sequential, descriptive study, taking place between 05. January 2007 and 22. January 2012. Patient enrolment began before study trial was registered (ClinicalTrials.gov Identifier: NCT01044641, https:/clinicaltrials.gov/ct2/show/

NCT01044641 ?term = guthe\&rank=2) due to the authors not being aware of the need for registration when the study was initiated. The authors confirm that all ongoing and related trials for this intervention are registered. The protocol was approved 29. September 2006 by the local ethics committee (Regional Committee for Medical and Health Research Ethics, Western Norway) and conducted at the outpatient clinic, Department of Ear-Nose-Throat, Haukeland University Hospital. Patients were also recruited from the Department of Ear-Nose-Throat, 
Akershus University Hospital from May 2010 to June 2010 to increase number of participants. Ethics approval was not necessary from Akershus University Hospital because of the existing approval from the Regional Committee for Medical and Health Research Ethics, Western Norway. For CONSORT checklist, Ethical Confirmation and Trial Protocol in Norwegian and English; see S1 CONSORT Checklist, S1 Ethics approval, S1 Protocol and S2 Protocol. The time period for patient recruitment was prolonged after approval from the local ethics committee, due to delayed enrolment of patients.

Patients were included in the study, after written informed consent was obtained from the parents or guardian. All subjects were recruited from otherwise healthy patients, 99 children (aged between 2 and 10 years), who were scheduled either for tonsillectomy and/or adenotomy and/or tympanic paracentesis. Enrolled subjects were excluded if they had any sign or significant medical history of acute febrile illness, underlying chronic diseases like cardiac anomalies, liver disease, nephropathy or any disease states and present medication that could interfere with protein metabolism. Age, gender and weight were plotted in pediatric national growth charts according to Juliusson [12].

Experiments were performed after a fasting period of at least 8 hours (no food, or chewing gum allowed after midnight the day on admission, only small amounts of water were allowed 2 hours before operation). Induction and maintenance of anesthesia consisted of weight related doses of sodium thiopental/propofol, fentanyl/remifentanil, morphine, atropine and mivacurium chloride (sevoflurane gas induction was used initially if intravenously cannulation failed). Rectal administration of paracetamol/paracetamol-kodein and non-steroidal anti-inflammatory drugs (NSAIDs) was performed after intubation, and controlled mechanical ventilation was adjusted according to end-expiratory carbon dioxide concentration and pulse oximetry. Maintenance fluid of Ringer's solution was administered according to local guidelines during the procedure and all medication were requested and handled by anesthetists who were not involved in the study.

Procedures: Included patients were divided into age specific subgroups $(2-3,4-5,6-7,8-10$ years) according to National Institute of Child Health and Human Development (NICHD) pediatric terminology where early childhood is defined from 2 to 5 years and middle childhood from 6 to 11 year [13]. After induction of anesthesia, sterilized multi-filamentous nylon wicks of approximately $5 \mathrm{~cm}$ were introduced in subcutis after skin disinfection and covered with adhesive plastic film in accordance with earlier wick studies [14]. Each patient had one wick implanted subcutaneously in one arm (lateral upper arm) at the level of the heart. This site was chosen since it was technically preferable to the thorax used in the original publication by Noddeland [11] and due to less and difficult accessible subcutaneous tissue of a small thorax. A second wick was placed in the medial part of one leg. All wicks were removed after 60 minutes according to optimal implantation/equilibration time in adults [15]. In an additional group, irrespective of age, where general anesthesia was expected to last for over 90 minutes, one wick was implanted in each medial part of the leg. One wick was retracted after 60 minutes and one wick after 90 minutes.

Plasma colloid osmotic pressure: Before surgery, in connection with peripheral intravenously cannula insertion, $0.5 \mathrm{ml}$ venous blood was collected after light hemostasis. Since coagulating factors are known to have sparse effect on COP [16], plasma were allowed to coagulate in unheparinized tubes and serum was separated from the sample by centrifugation, $3000 \mathrm{rpm}$ for 10 minutes, and immediately frozen in plastic tubes (Sarstedt, Reagiergefaße, micro tubes, $1,5 \mathrm{ml})$ at $-20^{\circ} \mathrm{C} \cdot \mathrm{COP}_{\mathrm{p}}$ was measured directly with a colloid osmometer designed for small fluid samples $[15,17,18]$ using a membrane impermeable for molecules $>30 \mathrm{kDa}(\mathrm{PM}-30$ Amicron, Lexington, Ma, USA). Signals were amplified and recorded (Easy Graph P930, Gould Inc., USA). 
Interstitial colloid osmotic pressure: After induction of anesthesia, two double threaded multi-filamentous nylon wicks were sewn into subcutaneous tissue. Methods and procedures were performed under sterile conditions and according to previous studies [15]. Blood stained wicks were discarded, and only clear and pink wicks with presumably none or low hemoglobin contamination were accepted for further evaluation [19]. $\mathrm{COP}_{\mathrm{i}}$ was measured directly by a colloid osmometer as described above.

Circulating blood volume (CBV) for estimation of blood loss during surgery was calculated by the following formula estimated from a recent meta-analysis by Riley et al [20].

$$
\mathrm{CBF}=75 \mathrm{ml} / \mathrm{kg} \text { bodyweight } \times \mathrm{kg} \text { bodyweight }
$$

Serum albumin and hemoglobin concentration were analyzed in an automatic analyzer (Cobas 8000 c702, Roche Diagnostics, USA and CELL-DYN Sapphire, Abbott Diagnostics, USA) respectively, both by colorimetry.

Bedside hemodynamic monitoring (blood pressure, heart rate and $\mathrm{SpO}_{2}$ ) was performed immediately before, under and after the procedure according to local protocol.

Statistical Analysis: Data were evaluated using SigmaStat 11 (Sy Stat Software/Inc.; Germany). Results are presented as numbers with proportions (\%) and means with standard deviation (SD). Statistically significance was defined as a P value $<0.05$. One-way ANOVA was used for evaluating the $\mathrm{COP}_{\mathrm{p}}$ and $\mathrm{COP}_{\mathrm{i}}$ between the different age groups, followed by an allpairwise Holm-Sidak multiple comparison procedure if there was found a statistical significance with the One-way ANOVA. When comparing smaller groups, not normally distributed, we used a non-parametric test (Mann-Whitney).

\section{Results}

Patients and outcome: A total of 99 children (45 girls and 54 boys), were included in the study (Fig 1), and 92 (93\%) had weights within \pm 2 SD according to Norwegian growth charts (S1 Fig). Eleven participants (mean age 4 years 8 months) had blood loss greater than $10 \%$ of estimated CBV (Fig 2). Nineteen percent of wicks were discarded due too blood staining of wick or insufficient sample size (Fig 2). In average, 51 of interstitial fluid was harvested from each wick. Preoperative hemoglobin $(\mathrm{Hb})$ measured in 83 patients (84\%) less than eight days before surgery averaged $12.5 \mathrm{~g} / \mathrm{dl}$ (range 10.5-15.0). Serum Albumin was measured before surgery in 32 patients (32\%) with mean albumin of $44 \mathrm{~g} / \mathrm{l}$ (range 38-52) and no statistical difference was found between the different age groups. There were no immediate (before discharge) or long time (phone interview 7 days after the procedure) complications due to wick implantation or blood sampling.

Plasma COP: Mean $\mathrm{COP}_{\mathrm{p}}$ for all age groups was $25.6 \pm 3.3 \mathrm{mmHg}$, and there was a significant rise from $24.6 \pm 3.2 \mathrm{mmHg}$ at $2-3$ years to $28 \pm 4.2 \mathrm{mmHg}$ at $8-10$ years of age, $\mathrm{P}=0.02$ (Fig 3).

Interstitial COP: Mean $\mathrm{COP}_{\mathrm{i}}$ (arm and leg together) for all children was $13.9 \pm 3.5 \mathrm{mmHg}$. There were no significant differences between the $2-3,4-5$ and 6-7 year age groups, $(14.2 \pm$ $3.2 \mathrm{mmHg}, 13.6 \pm 3.4 \mathrm{mmHg}$ and $13.2 \pm 4.1 \mathrm{mmHg}$ respectively), but the 8-10 age group had a higher value $(17.2 \pm 3.2 \mathrm{mmHg}$ ) than the younger children, $\mathrm{P}<0.05$ (Fig 3). There were no significant differences between arm and leg $\mathrm{COP}_{\mathrm{i}}$ within any of the groups or between groups (Fig 4). In contrast to the other groups, the $\mathrm{COP}_{\mathrm{i}}$ tended to be lower in the leg than in the arm in the 8-10 year old group, but observations were few. The mean $\mathrm{COP}_{\mathrm{i}}(\mathrm{arm}$ and leg altogether) from patients with blood loss over $10 \%$ of $\mathrm{CBV}$ was significantly higher than the $\mathrm{COP}_{\mathrm{i}}$ obtained from the other patients $(16.0 \pm 4.0 \mathrm{mmHg}$ vs. $14.0 \pm 3.6 \mathrm{mmHg}, \mathrm{P}=0.048)$. 


\section{ONSORT}

TRANSPARENT REPORTING of TRIALS

\section{CONSORT 2010 Flow Diagram}

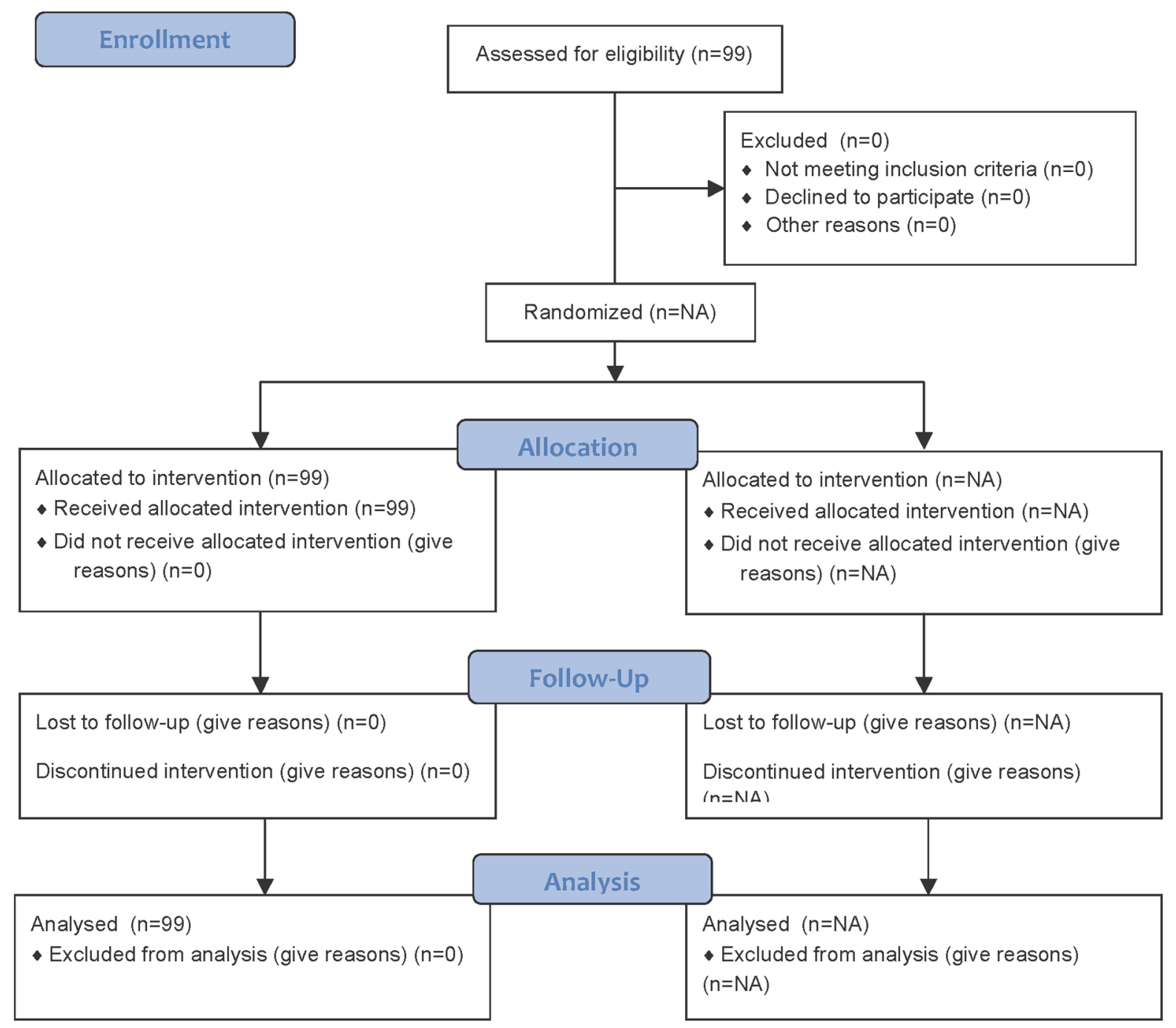

Fig 1. CONSORT flow diagram.

doi:10.1371/journal.pone.0122779.g001

Twenty-two patients who received NSAIDs in combination with paracetamol had almost identical $\mathrm{COP}_{\mathrm{i}}$ to those who did not receive NSAIDs $(14.1 \pm 3.9 \mathrm{mmHg}$ vs. $14.0 \pm 3.5 \mathrm{mmHg}$ $\mathrm{P}=0.9)$. 


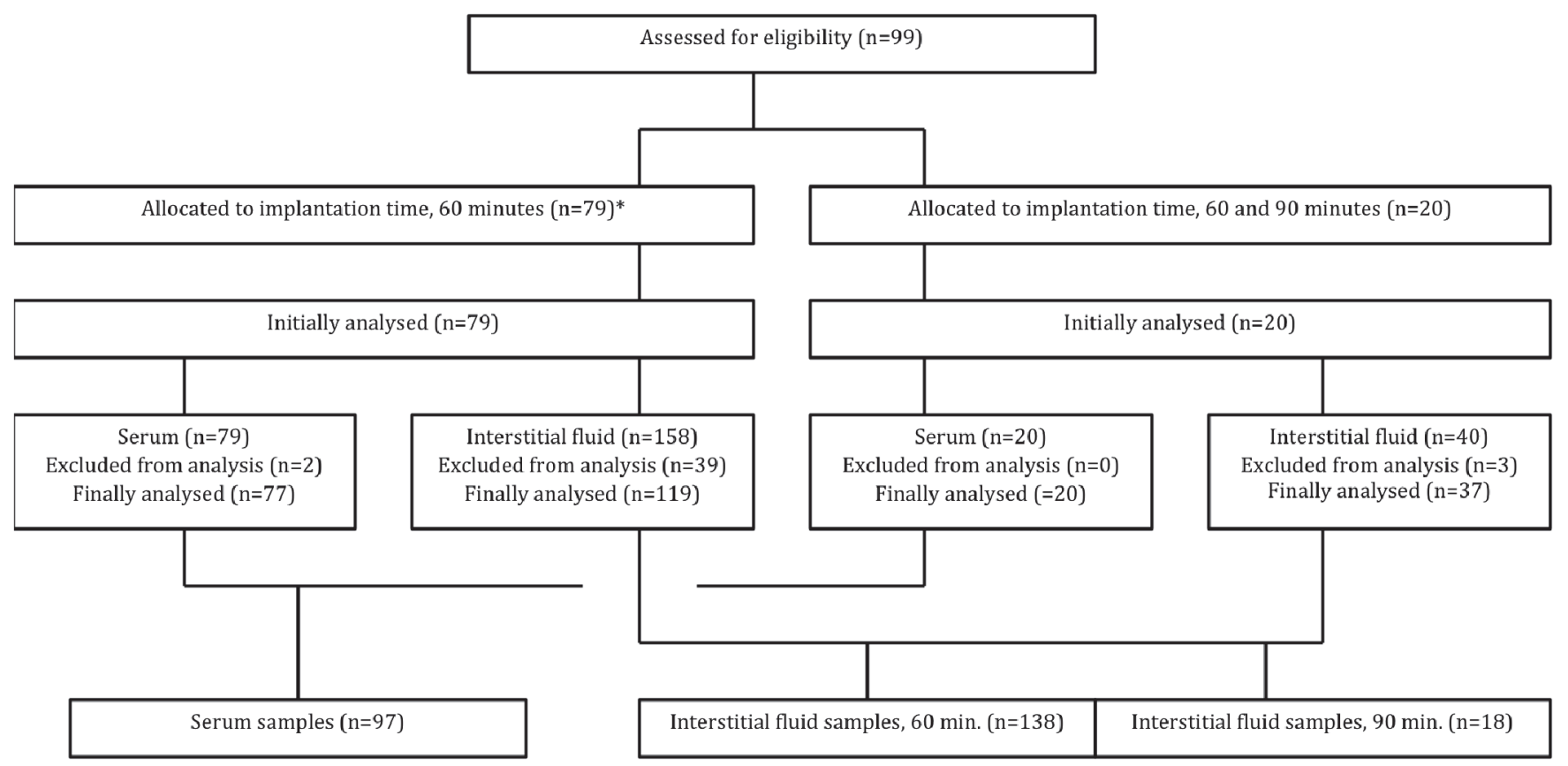

Fig 2. Recruitment of patients and distribution of samples. *Blood loss greater than $10 \%$ of estimated CBV $(n=11)$.

doi:10.1371/journal.pone.0122779.g002

Eighteen patients had wicks implanted in the leg for 60 and 90 minutes. There was no significant difference in mean $\mathrm{COP}_{\mathrm{i}}$ between these endpoints $(11.3 \pm 2.8 \mathrm{mmHg} v .12 .9 \pm 3.1 \mathrm{mmHg}$, $\mathrm{P}=0.11)$.

There was a significantly increasing colloid osmotic pressure gradient between plasma and interstitium $(\triangle \mathrm{COP})$ from $10.1 \pm 2.8 \mathrm{mmHg}$ at $2-3$ years to $14.5 \pm 3.9 \mathrm{mmHg}$ at $6-7$ years (Fig 5). The difference tended to be smaller for the $8-10$ year old group $(12.5 \pm 2.6 \mathrm{mmHg})$, but there were only five observations.

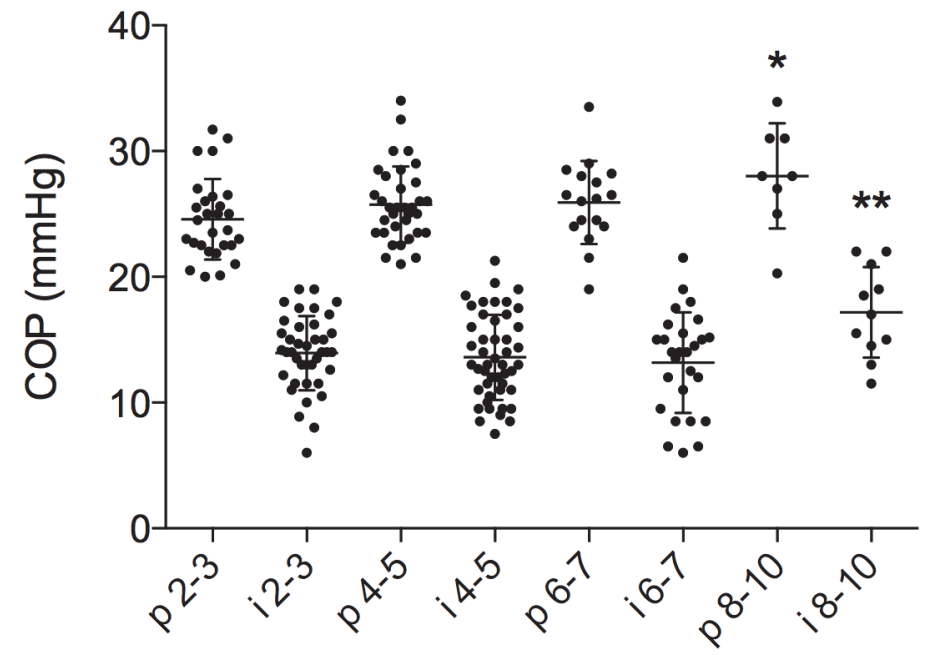

Fig 3. Colloid osmotic pressure in plasma and interstitium. Colloid osmotic pressure in plasma (p) and interstitium (i) (arm and leg merged) related to age. There was significant difference in pressures between 2-3 years and 8-10 years for plasma $\left(P<0.05,{ }^{*}\right)$ and between first three age groups and 8-10 years $\left(\mathrm{P}<0.01,{ }^{*}\right)$ in interstitial fluid.

doi:10.1371/journal.pone.0122779.g003 


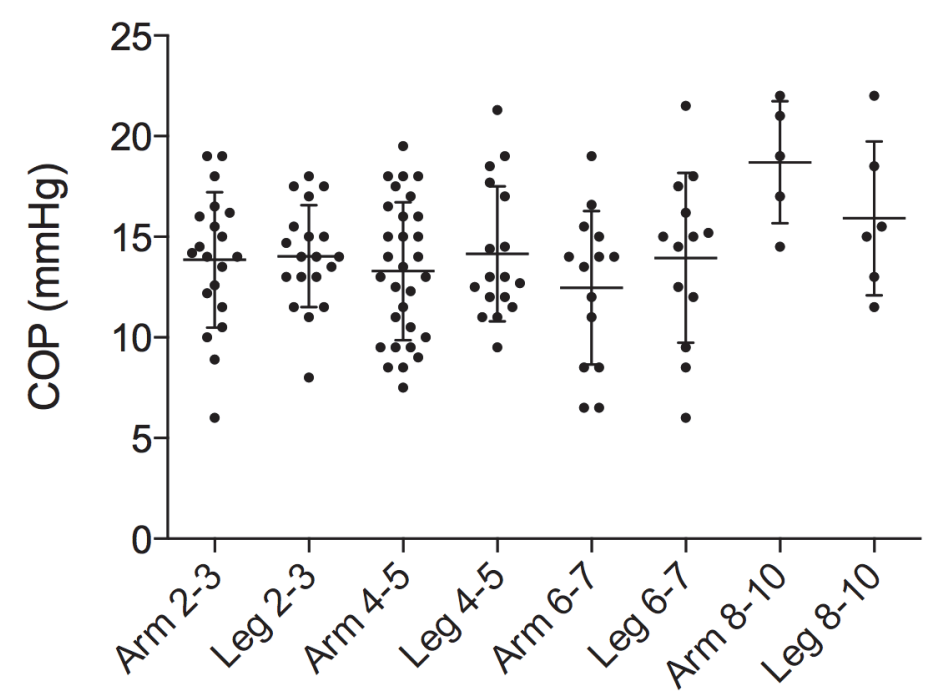

Fig 4. Colloid osmotic pressure in arm and leg. Colloid osmotic pressure from wicks after implantation in arm vs. leg related to age. There was no significant difference in the pressures obtained in arm and leg.

doi:10.1371/journal.pone.0122779.g004

\section{Discussion}

In this study, $\mathrm{COP}_{\mathrm{p}}$ and $\mathrm{COP}_{\mathrm{i}}$ in healthy children were close to what has been reported for healthy adults [21], but both $\mathrm{COP}_{\mathrm{p}}$ and $\mathrm{COP}_{\mathrm{i}}$ were significantly higher at 8-10 years than in younger children. Whether $\mathrm{COP}_{\mathrm{i}}$ was obtained at or below heart level, or after 60 or $90 \mathrm{~min}$ utes, did not influence the results. There were no complications to using nylon wicks, suggesting that this method is safe for harvesting IF in anesthetized children. Furthermore, the method also gave sufficient volumes of IF to allow COP measurements. In rats, the optimal time needed for fluid and protein transport into the wick with a minimum of inflammation is between 30 and 120 minutes [19]. As suggested for healthy adults [14, 15], we found that 60 minutes was sufficient implantation time for collection of IF.

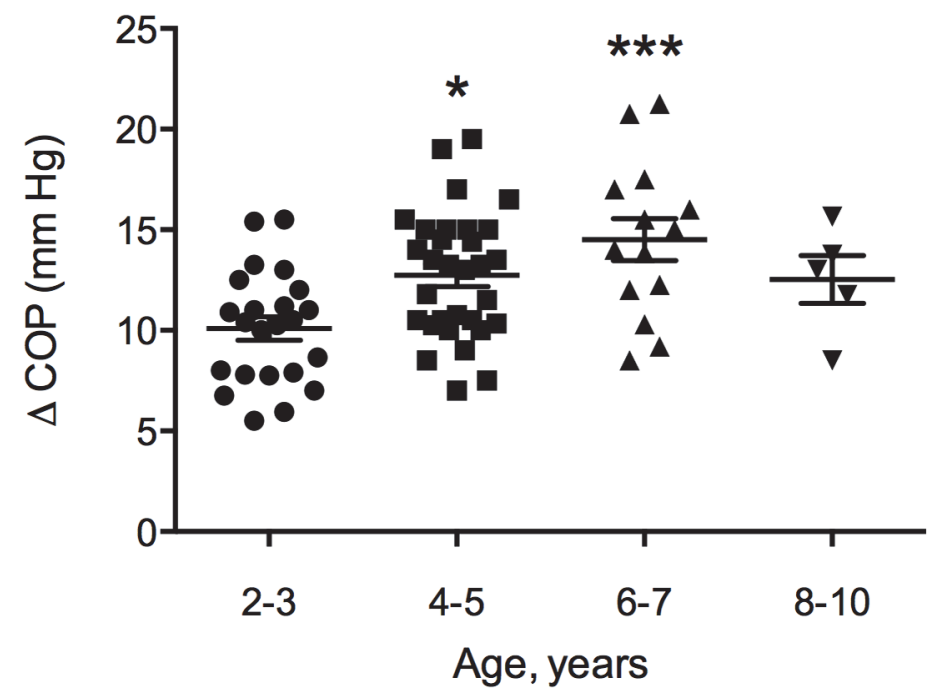

Fig 5. Transcapillary gradient in COP. $\left(\triangle \mathrm{COP}=\mathrm{COP}_{\mathrm{p}}-\mathrm{COP}_{\mathrm{i}}\right.$ (arm and leg merged)) $\triangle \mathrm{COP}$ related to age, with significant difference between $4-5$ years and $2-3$ years $\left(P=0.017^{*}\right)$ and between $6-7$ years and $2-3$ years $\left(\mathrm{P}<0.001^{* * *}\right)$.

doi:10.1371/journal.pone.0122779.g005 
Earlier studies by Noddeland showed a significant higher $\mathrm{COP}_{\mathrm{i}}$ in the thorax wall than in the calf close to the ankle in adults who were examined both in the upright and horizontal position, and that the duration of horizontal positioning did not change $\mathrm{COP}_{\mathrm{i}}$ significantly up to 40 hours [11]. We did not observe such difference in our population although the children had been freely ambulatory until shortly before the relatively minor surgical procedures. The duration of horizontal position was not recorded, but lasted at least 1 hour before sampling. Our finding of no significant difference between arm and leg $\mathrm{COP}_{\mathrm{i}}$ suggests that children do not experience the same orthostatic effects on $\mathrm{COP}_{\mathrm{i}}$ as adults. This conclusion is underscored by the observation that the $\mathrm{COP}_{\mathrm{i}}$ in the leg was lower than in the arm for the age group closest to adulthood, but not in the younger children. The difference between adults and children may have several explanations, e.g. a larger orthostatic effect due to a greater height and poorer venous drainage as a consequence of the characteristics of the veins or less physical activity.

In accordance with earlier data of $\mathrm{COP}_{\mathrm{i}}$ in ankle [11], this finding indicates that duration of implantation within these limits did not cause sufficient trauma and subsequent inflammation to produce changes in interstitial protein distribution, which may have been expected to increase with increased implantation time [22].

$\mathrm{COP}_{\mathrm{p}}$ in healthy full-term $(19.4 \pm 2.2 \mathrm{mmHg})$ [23] and pre-term $(15.4 \pm 1.3 \mathrm{mmHg})$ [24] babies have been reported to be significantly lower than in healthy infants from 1 to 9 months of age [6], who may have values almost identical to that of adults $(25 \mathrm{mmHg})$ [21]. Due to lack of data on changes in COP in infants up to 2 post-natal months, we anticipate a sharp increase in $\mathrm{COP}$ to occur within the first months of life. Our findings of $\mathrm{COP}_{\mathrm{p}}$ and $\mathrm{COP}_{\mathrm{i}}$ similar to what has been reported for patients from two years of age are in line with studies beyond the neonatal period, suggesting that the major change occurs at around 1-2 months of age, although our study documents that a small, but significant increase also occurs during early childhood. This rise of $\mathrm{COP}_{\mathrm{p}}$ is probably due to increasing serum concentration of proteins other than albumin, which is known to occur with increasing age [25] since we experienced a concomitant elevation in both $\mathrm{COP}_{\mathrm{p}}$ and $\mathrm{COP}_{\mathrm{i}}$ and no age dependent change in preoperative serum albumin.

$\mathrm{COP}_{\mathrm{p}}$ in healthy subjects is predominantly dependent on plasma albumin and to a lesser extent on the total plasma protein concentration [26]. Albumin concentrations in the premature infant are lower than in term newborns [27], increase gradually up to 1 years of age and then undergo a modest rise towards adulthood [25]. The apparent parallel increase in $\mathrm{COP}_{\mathrm{p}}$ and albumin concentration, therefore, suggests that albumin is part of the cause of the age dependent $\mathrm{COP}_{\mathrm{p}}$.

The use of hyperoncotic albumin in diseased states for fluid replacement and maintenance of $\mathrm{COP}_{\mathrm{p}}$ is controversial and has not proven superior to saline with respect to mortality for adults admitted to the intensive care unit needing fluid resuscitation e.g. [28, 29]. In critically ill patients with increased vascular permeability, administration of albumin may actually worsen edema due to leakage of albumin into the interstitium with concomitant elevation of $\mathrm{COP}_{\mathrm{i}}$ and intensified accumulation of interstitial fluid. There is a correlation between low $\operatorname{COP}_{\mathrm{p}}$ at birth and severity of respiratory distress syndrome [30] and detection of early hypoproteinemia in sick preterm babies is associated with unfavorable outcome [31].

Blunt et al found a reduced contribution of albumin from $80 \%$ to $17 \%$ in relation to $\mathrm{COP}_{\mathrm{p}}$ in sick patients [32] with no proven effect of albumin administration on mortality. Although there is a reasonable link between $\mathrm{COP}_{\mathrm{p}}$ and albumin these findings may advocate reduced serum albumin simply as a marker of serious disease rather than an indicator of decreased $\mathrm{COP}_{\mathrm{p}}$. There are few studies addressing albumin for fluid resuscitation in the pediatric population, and albumin is now less used as standard plasma expander in infants although potentially beneficial for children undergoing cardiopulmonary bypass [8]. 
Accurate measurement of CBV in children is difficult due to lack of a "gold" standard method. However, a recent meta-analysis of values from many small studies showed that a CBV of $75 \mathrm{ml} / \mathrm{kg}$ appears to be normal for children from 2 years of age [20]. A blood loss between 10\% to $15 \%$ of estimated CBV (equivalent to Class 1 hemorrhage in adults, i.e. mild blood loss) in healthy children will only cause no more than mild tachycardia [33]. By excluding patients with blood loss above $10 \%$, which may possible influence hemodynamic, untoward effects of blood loss on COP were probably eliminated. Excessive provision of fluid will decrease $\mathrm{COP}_{\mathrm{p}}$ and also decrease $\mathrm{COP}_{\mathrm{i}}$ subsequent to increased filtration of fluid into the interstitium. Approximately $80 \%$ of the patients received fluid in excess of basic needs during the surgical procedure, but they were not given fluids during several hours before surgery and it is likely that the fluid balance was within normal levels at the time of sampling. Therefore, it is reasonable to assume that our data on COP represented normal physiological values.

We found a significant increase in $\triangle \mathrm{COP}$ from 2 to 7 years. Such increase will favor transport of fluid into the capillaries and concurrent reduced absorption of fluid by the lymphatic system in order to preserve homeostasis. Earlier studies have shown that a local rise in $\mathrm{COP}_{\mathrm{p}}$ will counteract edema formation in tissue with reduced blood flow [34], as observed in our study, where $\mathrm{COP}_{\mathrm{p}}$ and lymph drainage is thought to be important. A reduced $\Delta \mathrm{COP}$ for $8-10$ years is probably due to higher $\mathrm{COP}_{\mathrm{i}}$ compared to a net increase in $\mathrm{COP}_{\mathrm{p}}$ with age. Whether this decline in delta COP is caused by a hydrostatic effect of patients being taller or a result of few observations remains uncertain.

$\mathrm{COP}_{\mathrm{i}}$ is, together with interstitial hydrostatic pressure, $\mathrm{COP}_{\mathrm{p}}$ and lymph flow, important regulators of interstitial fluid balance. These factors may also counteract edema formation in situations with hyperfiltration. Recording of interstitial fluid pressure $\left(\mathrm{P}_{\mathrm{i}}\right)$ in relation to $\mathrm{COP}_{\mathrm{p}}$ and $\mathrm{COP}_{\mathrm{i}}$ would have been useful, but this was not feasible under the current clinical conditions.

In a revision of the traditional form of Starling's principle, Levick and Michel advocate that $\mathrm{COP}_{\mathrm{i}}$ in the "global" tissue at a distance from the capillary has less effect on capillary filtration than previously anticipated due to the presence of a semipermeable endothelial glycocalyx layer (EGL) built up of glycoproteins and glycosaminoglycanes [35]. The EGL will result in a $\mathrm{COP}$ gradient into the capillary that is higher than that calculated from $\triangle \mathrm{COP}$. A recent review by Woodcock and Woodcock emphasizes that maintenance of the integrity of EGL might be of significance for fluid resuscitation to support the circulation in high filtration states [36]. The conclusions of a reduced importance of the $\mathrm{COP}_{\mathrm{i}}$ in fluid filtration originates from experiments with high filtration pressures, whereas studies in mesenteric capillaries of rats suggests that the oncotic transcapillary pressure gradient is highly filtration dependent and that $\mathrm{COP}_{\mathrm{i}}$ is close to COP of EGL at normal filtration pressures [37]. As recently discussed by Wiig and Swartz [38], with these reservations, we may still conclude that $\mathrm{COP}_{\mathrm{i}}$ is of major importance for normal fluid filtration.

The present study has some limitations. All subjects were under general anesthesia and, therefore, may have had altered homeostasis, which could impinge upon normal COP values, although maintenance of anesthesia with propofol is associated with minimal fluid extravasation [39]. Due to our protocol, additional implantation of wicks was not accepted when traumatic bleeding occurred, which reduced the number of simultaneous determination of COP in plasma and IF. Plasma COP should optimally be sampled at the same time as harvesting the wicks, not only before implantation. This is especially important for patients with traumatic bleeding over $10 \%$ of CBV since a fall in hematocrit probably would alter $\mathrm{COP}_{\mathrm{p}}$ as well as $\mathrm{COP}_{\mathrm{i}}$. Due to our protocol, and the wish to avoid harmful procedures in non-therapeutic research, it was not possible to sample blood after discontinuation of anesthesia. 
In conclusion, children between 2 and 10 years of age have plasma COP values similar to adults, with raised $\mathrm{COP}_{\mathrm{p}}$ and $\mathrm{COP}_{\mathrm{i}}$ with increasing age. These findings are important to acknowledge, since small alterations in the pressure gradient over the capillary membrane can cause substantial fluid shifts. Increasing knowledge of COP in both health and disease and the influence of crystalloids, colloids and diuretics on COP may be beneficial optimizing clinical care both in adults and the pediatric population.

\section{Supporting Information}

S1 Checklist. CONSORT Checklist.

S1 Ethics approval. Ethical Confirmation from the Regional Committee for Medical and Health Research Ethics, Western Norway. (PDF)

S1 Fig. Weight and standard deviation according to Norwegian growth charts. 2 SD equals 97.7 percentile and -2 SD equals 2.3. percentile.

(PDF)

S1 Protocol. Trial protocol in Norwegian.

(PDF)

S2 Protocol. Trial protocol in English.

(PDF)

\section{Acknowledgments}

The authors are grateful to Petur Juliusson for contributing with growth references in this study and Trond Markestad for valuable and helpful comments on the manuscript.

\section{Author Contributions}

Conceived and designed the experiments: AB HW HJTG TN GN MI. Performed the experiments: HJTG AB MI GN TN HW. Analyzed the data: HJTG MI TN AB HW GN. Contributed reagents/materials/analysis tools: HW AB HJTG TN MI GN. Wrote the paper: HJGU AB HW TN MI GN.

\section{References}

1. Starling EH. On the Absorption of Fluids from the Connective Tissue Spaces. J Physiol (Lond). 1896; 19: 312-326. PMID: 16992325

2. Noddeland $\mathrm{H}$, Riisnes SM, Fadnes $\mathrm{HO}$. Interstitial fluid colloid osmotic and hydrostatic pressures in subcutaneous tissue of patients with nephrotic syndrome. Scand J Clin Lab Invest. 1982; 42: 139-146. PMID: 7134798

3. Tollan A, Oian P, Fadnes HO, Maltau JM. Evidence for altered transcapillary fluid balance in women with the premenstrual syndrome. Acta Obstet Gynecol Scand. 1993; 72: 238-242. PMID: 8389508

4. Oian $\mathrm{P}$, Maltau JM, Noddeland H, Fadnes HO. Oedema-preventing mechanisms in subcutaneous tissue of normal pregnant women. Br J Obstet Gynaecol. 1985; 92: 1113-1119. PMID: 4063227

5. Golab H, Takkenberg J, Bogers A. Risk factors for low colloid osmotic pressure during infant cardiopulmonary bypass with a colloidal prime. Interactive CardioVascular and Thoracic Surgery. 2009; 8(5): 512-516. doi: 10.1510/icvts.2008.198283 PMID: 19188213

6. Sussmane JB, de Soto M, Torbati D. Plasma colloid osmotic pressure in healthy Infants. Crit Care. 2001; 5: 261-264. PMID: 11737900

7. Toye JM, Lemire EG, Baerg KL. Perinatal and childhood morbidity and mortality in congenital analbuminemia. Paediatr Child Health. 2012; 17(6): e20-23. PMID: 23730173 
8. Golab HD, Scohy TV, de Jong PL, Kissler J, Takkenberg JJ, Bogers AJ. Relevance of colloid oncotic pressure regulation during neonatal and infant cardiopulmonary bypass: a prospective randomized study. Eur J Cardiothorac Surg. 2011; 39: 886-891. doi: 10.1016/j.ejcts.2010.09.040 PMID: 21055963

9. Aukland K, Reed RK. Interstitial-lymphatic mechanisms in the control of extracellular fluid volume. Physiol Rev. 1993; 73: 1-78. PMID: 8419962

10. Aukland K, Reed RK, Wiig H. The problem of gaining access to interstitial fluid. An attempt to rationalize a wicked discussion on wicks. Lymphology. 1997; 30: 111-115. PMID: 9313202

11. Noddeland $\mathrm{H}$. Influence of body posture on transcapillary pressures in human subcutaneous tissue. Scand J Clin Lab Invest. 1982; 42: 131-138. PMID: 7134797

12. Juliusson PB, Roelants M, Nordal E, Furevik L, Eide GE, Moster D, et al. Growth references for 0-19 year-old Norwegian children for length/height, weight, body mass index and head circumference. Ann Hum Biol. 2013; 40: 220-227. doi: 10.3109/03014460.2012.759276 PMID: 23414181

13. NICHD Pediatric Terminology. Available: http://www.nichd.nih.gov/health/clinicalresearch/clinicalresearchers/terminology/Publishinglmages/Child_Life_Stages.jpg. Accessed 01 January 2015.

14. Noddeland $\mathrm{H}$. Colloid osmotic pressure of human subcutaneous interstitial fluid sampled by nylon wicks: evaluation of the method. Scand J Clin Lab Invest. 1982; 42: 123-130. PMID: 7134796

15. Guthe HJ, Nedrebo T, Tenstad O, Wiig H, Berg A. Effect of topical anaesthetics on interstitial colloid osmotic pressure in human subcutaneous tissue sampled by wick technique. PLoS One. 2012; 7: e31332. doi: 10.1371/journal.pone.0031332 PMID: 22348071

16. Aukland K, Noddeland H, Hommel E. Measurement of colloid osmotic pressure in body fluids: errors caused by preheparinized glass capillaries and by CO2 loss. Scand J Clin Lab Invest. 1987; 47: 331335. PMID: 3110936

17. Wiig $\mathrm{H}$, Halleland $\mathrm{EG}$, Fjaertoft $\mathrm{M}$, Aukland $\mathrm{K}$. Measurement of colloid osmotic pressure in submicrolitre samples. Acta Physiol Scand. 1988: 132: 445-452. PMID: 3227885

18. Aukland K, Johnsen HM. A colloid osmometer for small fluid samples. Acta Physiol Scand. 1974; 90 : 485-490. PMID: 4823020

19. Aukland K, Fadnes HO. Protein concentration of interstitial fluid collected from rat skin by a wick method. Acta Physiol Scand. 1973; 88: 350-358. PMID: 4751172

20. Riley AA, Arakawa Y, Worley S, Duncan BW, Fukamachi K. Circulating blood volumes: a review of measurement techniques and a meta-analysis in children. ASAIO J. 2010; 56: 260-264. doi: 10.1097/ MAT.0b013e3181d0c28d PMID: 20335800

21. Weil MH, Morissette M, Michaels S, Bisera J, Boycks E, Shubin $\mathrm{H}$, et al. Routine plasma colloid osmotic pressure measurements. Crit Care Med 1974; 2: 229-234. PMID: 4455449

22. Fadnes $\mathrm{HO}$, Aukland K. Protein concentration and colloid osmotic pressure of interstitial fluid collected by the wick technicue: Analysis and evaluation of the method. Microvascular Research. 1977; 14: 1125. PMID: 895541

23. Sola A, Gregory GA. Colloid osmotic pressure of normal newborns and premature infants. Crit Care Med. 1981; 9: 568-572. PMID: 7196309

24. Bhat R, Javed S, Malalis L, Vidyasagar D. Critical care problems in neonates. Colloid osmotic pressure in healthy and sick neonates. Crit Care Med. 1981; 9: 563-567. PMID: 7261639

25. Ghoshal AK, Soldin SJ. Evaluation of the Dade Behring Dimension RxL: integrated chemistry systempediatric reference ranges. Clin Chim Acta. 2003; 331: 135-146. PMID: 12691874

26. Weil MH, Henning RJ, Puri VK. Colloid oncotic pressure: clinical significance. Crit Care Med. 1979; 7: 113-116. PMID: 436426

27. Zlotkin $\mathrm{SH}$, Casselman CW. Percentile estimates of reference values for total protein and albumin in sera of premature infants (less than 37 weeks of gestation). Clin Chem. 1987; 33: 411-413. PMID: 3102125

28. Finfer S, Bellomo R, Boyce N, French J, Myburgh J, Norton R. A comparison of albumin and saline for fluid resuscitation in the intensive care unit. N Engl J Med. 2004; 350: 2247-2256. PMID: 15163774

29. Perel $\mathrm{P}$, Roberts I, Ker K. Colloids versus crystalloids for fluid resuscitation in critically ill patients. Cochrane Database Syst Rev. 2013; 2: CD000567.

30. Zimmermann B, Francoise M, Germain JF, Lallemant C, Gouyon JB. Colloid osmotic pressure and neonatal respiratory distress syndrome. Arch Pediatr. 1997; 4: 952-958. PMID: 9436492

31. lacobelli S, Bonsante F, Quantin C, Robillard PY, Binquet C, Gouyon JB. Total plasma protein in very preterm babies: prognostic value and comparison with illness severity scores. PLoS One. 2013; 8 : e62210. doi: 10.1371/journal.pone.0062210 PMID: 23614036

32. Blunt MC, Nicholson JP, Park GR. Serum albumin and colloid osmotic pressure in survivors and nonsurvivors of prolonged critical illness. Anaesthesia. 1998; 53: 755-761. PMID: 9797519 
33. Nichols DG. Rogers' Textbook of Pediatric Intensive Care: Philadelphia: Lippincott Williams \& Wilkins. In: Baird JS, Cooper A. Multiple Trauma; 2008. pp. 384-407.

34. Noddeland $\mathrm{H}$, Aukland K, Nicolaysen G. Plasma colloid osmotic pressure in venous blood from the human foot in orthostasis. Acta Physiol Scand. 1981; 113: 447-454. PMID: 7348029

35. Levick JR, Michel CC. Microvascular fluid exchange and the revised Starling principle. Cardiovasc Res. 2010; 87: 198-210. doi: 10.1093/cvr/cvq062 PMID: 20200043

36. Woodcock TE, Woodcock TM. Revised Starling equation and the glycocalyx model of transvascular fluid exchange: an improved paradigm for prescribing intravenous fluid therapy. Br J Anaesth. 2012; 108: 384-394. doi: 10.1093/bja/aer515 PMID: 22290457

37. Adamson RH, Lenz JF, Zhang X, Adamson GN, Weinbaum S, et al. Oncotic pressures opposing filtration across non-fenestrated rat microvessels. J Physiol. 2004; 557: 889-907. PMID: 15073281

38. Wiig $\mathrm{H}$, Swartz MA. Interstitial fluid and lymph formation and transport: physiological regulation and roles in inflammation and cancer. Physiol Rev. 2012; 92: 1005-1060. doi: 10.1152/physrev.00037. 2011 PMID: 22811424

39. Brekke HK, Hammersborg SM, Lundemoen S, Mongstad A, Kvalheim VL, Haugen O, et al. Isoflurane in Contrast to Propofol Promotes Fluid Extravasation during Cardiopulmonary Bypass in Pigs. Anesthesiology. 2013; 119: 861-870. doi: 10.1097/ALN.0b013e31829ab018 PMID: 23719612 